Revista General de Información y Documentación ISSN: $1132-1873$

http://dx.doi.org/10.5209/RGID.58208

\title{
Estudio de las encuadernaciones de Jacques-Nicolas Colbert depositadas en la Biblioteca Complutense
}

\author{
José María de Francisco Olmos ${ }^{1}$; Antonio Carpallo Bautista ${ }^{2}$
}

Recibido: 23 septiembre 2017 / Aceptado: 17 de noviembre de 2017

Resumen. Este trabajo estudia las encuadernaciones de la familia Colbert depositadas en la Biblioteca Histórica Marqués de Valdecilla de la Universidad Complutense de Madrid. Este primer estudio persigue identificar los superlibris de Jacques-Nicolas Colbert, Arzobispo de Rouen, que aparecen en las tapas, ayudados por los diferentes tipos de anagramas y estructuras decorativas de los entrenervios; también se estudian los materiales y las técnicas de construcción de las encuadernaciones, la decoración del lomo (nervios y entrenervios), cantos, contracantos, cofias y guardas, muchas de ellas decoradas con papeles marmoleados, así como su estado de conservación.

Palabras clave: Identificación de encuadernaciones; Reconstrucción de bibliotecas; Antiguos poseedores; Colbert, Jacques-Nicolas, Arzobispo de Rouen (1655-1707); Colbert, Jean Baptiste, Marqués de Seignelay (1619-1683)

\section{[en] Study of bookbindings of Jacques-Nicolas Colbert deposited at the Complutense Library}

\begin{abstract}
This investigation studies the bindings of the family Colbert deposited in the Historical Library Marquess of Valdecilla of the Complutensian University of Madrid. This first study tries to identify the superlibris of Jacques-Nicolas Colbert, Archbishop of Rouen, which appear on a covers of books, helped by the different types of anagrams and decorative structures of the box; also there are studied the materials and the technologies of construction of the bindings, the decoration of the loin (bands and panel area between the bands), top of head edge, square, head-cap and endpaper, many of them decorated with marbled papers, as well as his condition of conservation.

Keywords: Identification of bindings; Reconstruction of libraries; Holders owners; Colbert, JacquesNicolas, Archbishop of Rouen (1655-1707); Colbert, Jean Baptiste, Marquess of Seignelay (16191683)
\end{abstract}

Sumario. 1. Introducción. 2. Encuadernaciones de Jacques-Nicolas Colbert (1655-1707), Abad de Bec-Hellouin, Arzobispo titular de Cartago, coadjutor y luego Arzobispo de Rouen. 3. Referencias Bibliográficas. 4. Cuadro resumido de la familia Colbert.

1 Universidad Complutense de Madrid. Facultad de Ciencias de la Documentación E-mail: josemafr@ucm.es

2 Universidad Complutense de Madrid. Facultad de Ciencias de la Documentación

E-mail: acarpall@ucm.es 
Cómo citar: de Francisco Olmos, J.M., Carpallo Bautista, A. (2017) Estudio de las encuadernaciones de Jacques-Nicolas Colbert depositadas en la Biblioteca Complutense, en Revista General de Información y Documentación 27 (2), 551-571.

\section{Introducción}

El trabajo de investigación ${ }^{3}$ que presentamos a continuación trata de identificar, analizar y estudiar las encuadernaciones artísticas depositadas en la Biblioteca Complutense de la familia Colbert, realizadas en París entre finales del siglo XVII y el primer cuarto del siglo XVIII, y que pertenecieron originalmente a la Biblioteca de Jean-Baptiste Colbert ${ }^{4}$ y sus herederos.

Para la realización de este estudio la metodología seguida ha sido comenzar con la realización de un inventario de todas las encuadernaciones artísticas y con elementos heráldicos en las tapas de la Biblioteca Histórica Marqués de Valdecilla de la Universidad Complutense de Madrid; seguidamente se realizó una selección de las encuadernaciones con emblemas de la familia Colbert, donde se localizaron un total de sesenta y siete ejemplares; a continuación comenzó el trabajo de estudio e identificación de cada uno de los superlibris estampados en las tapas y los elementos dorados de los entrenervios en función de la época de cada obra, así como el análisis otros aspectos como los materiales empleados en la encuadernación, las técnicas utilizadas en la construcción, las técnicas y estructuras decorativas, utensilios y el estado de conservación de cada ejemplar, con el objetivo de identificar cada uno de los antiguos poseedores de la familia Colbert, determinando también si eran encuadernaciones salidas del mismo taller y la datación aproximada de cada una. Para este trabajo se han consultado documentos sobre la biblioteca de la familia Colbert $^{5}$ depositados en la Biblioteca Nacional de España, Biblioteca de la Universidad de Salamanca y en la Biblioteca de la Casa Velázquez.

3 Este trabajo forma parte del proyecto de investigación $\mathrm{I}+\mathrm{D}$ promovido por el Ministerio de Ciencia e Innovación titulado "Estudio, identificación y catalogación automatizada de las encuadernaciones artísticas de la Biblioteca Histórica de la Universidad Complutense de Madrid y de la Biblioteca Histórica del Ayuntamiento de Madrid" (FFI2008-02604/FILO) y de las líneas de investigación de los grupos de investigación de la Universidad Complutense de Madrid denominados Bibliopegia: grupo de investigación sobre encuadernación y el libro antiguo (941369) y Numismática e investigación documental y epigráfica (941301).

4 Jean-Baptiste Colbert (1619-1683), Marqués de Seignelay (1668), conocido como el Gran Colbert, hijo mayor de Nicolás Colbert, señor de Vandieres, y de Mariane Pussort. Estudió en los jesuitas, entró pronto en la administración y el Cardenal Mazarino le encargó la gestión de su fortuna (1651-1661), fue clave en la caída de Fouquet y el Rey confió en él como intendente de Finanzas (1661-1665), superintendente de Correos, artes y manufacturas (1661-1683), controlador general de Finanzas (1665-1683), Secretario de Estado de la Casa del Rey y de la Marina (1669-1683), etc. Apoyó a la ciencia y las artes con la creación de las Reales Academias y formó una magnífica biblioteca.

5 Bibliotheca Colbertina. (1727). Parisiis: Gabrielem Martin y Franciscum Montalant.; BLOCH, D. (19891992). La bibliothèque de Colbert. Oliver, B. W y Anghelescu, H. G. B. Histoire des bibliothèques françaises. Paris: Promodis-Editions du Cercle de la Librairie, pp. 157-175.; Catalogue des livres de M. le marquis de Torcy (1755), Paris, Barrois.; Catalogus librorum Bibliothecae illustrississimi ac reverendissimi D.D. CaroliJoachimi Colbert de Croissi episcopi Montispessulani (1740). [Francia?: s.n.], 2 T. Sobre las encuadernaciones familiares de los Colbert puede verse una aproximación a las mismas en OLIVIER, E., HERMAL, G. y ROTON, R. de (1924-1938). Manuel de l'amateur de reliures armoriées françaises. Paris: Ch. Bosse, 30 T., planches 1296-1307, y en COLLET, A. (1999). "Bibliotecae Colbertinae: recherches sur 
A la muerte de Jean-Baptiste Colbert en 1683 se realizó un inventario de sus bienes, entre ellos de la famosa biblioteca con 41.844 libros que se dividieron en 20.000 impresos aproximadamente, 5.210 manuscritos antiguos y 13.014 diferentes obras. La biblioteca pasó a manos de su primogénito Jean-Baptiste Antoine Colbert ${ }^{6}$ que la mantuvo intacta hasta su muerte en 1690; en esos años aumentó sus fondos en cerca de setecientos impresos y cuatrocientos cincuenta manuscritos.

La biblioteca fue vendida por sus albaceas, en nombre de sus hijos, por entonces menores, a su hermano Jacques-Nicolas Colbert ${ }^{7}$, Arzobispo de Rouen. A su muerte (1707) legó la biblioteca familiar a su sobrino, Charles-Eléonore Colbert, por entonces $\mathrm{abad}^{8}$ y luego Conde de Seignelay, ya que abandonó la carrera eclesiástica y se casó en 1717 con Anne de la Tour et Taxis (m.1719) y en 1726 con Marie Renée de Gontaut-Biron (m.1775), hija del Duque de Biron. Su nueva vida y gastos le hicieron tomar la decisión de vender la Biblioteca, y las autoridades estaban alertadas de este hecho.

La venta pública de los libros impresos se realizó entre el 24 de mayo y el 21 de octubre de 1726. El año siguiente Seignelay vendió seiscientos volúmenes a François Nicolas Meigret de Serilly por 12.000 libras, y fue entonces cuando se produjeron conversaciones con los representantes de la Biblioteca Real para la adquisición de los manuscritos antiguos y de ciencia. Entonces comenzaron unas largas negociaciones sobre qué parte de la colección quería adquirir el Rey y a qué coste (1728-1732); al final el Conde de Seignelay ofreció todo lo que conservaba de la Biblioteca y dejaba que el Rey fijara la cuantía de la venta.

Luis XV aceptó el ofrecimiento y fijó su precio en 300.000 libras. Los fondos se transportaron desde la rue de Bourbon-Saint-Sulpice a la Biblioteca Real entre el 11 y el 13 de septiembre a excepción de los documentos del Cardenal Mazarino que fueron depositados en el archivo del Ministerio de Asuntos Exteriores. El fondo adquirido por la Biblioteca Real se componía de 6.070 manuscritos antiguos (637 orientales, 870 griegos, 3.582 latinos, 818 franceses, 114 italianos, 36 españoles, 4 portugueses, 4 holandeses, 3 alemanes y 2 ingleses), 984 originales y 1.717 manuscritos modernos.

quelques livres ayant appartenu à Jean Baptiste, Nicolas et Jacques-Nicolas Colbert”, en Des livres et des hommes: 1989-1999. Saint-Étienne Cedex: Université, pp. 155-162.

6 Jean-Baptiste Antoine Colbert (1651-1690), conocido como el Marqués de Seignelay, estudió en los jesuitas, sucedió a su padre como Secretario de Estado de la Marina (1683-1690). Entre sus hijos destaca la figura de Charles-Eléonore Colbert (1689-1747), Conde de Seignelay último propietario de la biblioteca Colbert vendida en 1728 .

7 Jacques-Nicolas Colbert (1655-1707) fue el segundo hijo varón del Gran Colbert. Educado para entrar en la iglesia, bajo la tutela de Noël Alexandre, un teólogo dominico y filósofo. Recibió en 1664 la Abadía de BecHellouin y el señorío temporal y espiritual del Priorato de la Charité-sur-Loire, y poco después obtuvo la abadía de Ambierle y otras posesiones. Doctor en la Sorbona, fue miembro de la Academia Francesa el 29 de octubre de 1678. Ordenado sacerdote el 6 de abril de 1679, fue nombrado arzobispo titular de Cartago y coadjutor del arzobispado de Rouen (1680), alcanzando este puesto en 1691. Murió en París el 10 de diciembre de 1707 y fue enterrado en la iglesia de Saint-Eustache.

8 El testamento del Arzobispo (5 de diciembre de 1707) era muy claro respecto de la Biblioteca y su conservación, por lo cual no la legó al hijo mayor de su hermano, Marie Jean Baptiste Colbert, III Marqués de Seignelay (m.1712), a quien recomendaba que su hermano menor, Charles, que por entonces era abad, conocido como el Abad de Seignelay, podría dedicar más tiempo y recursos a hacer crecer y conservar la gran Biblioteca familiar. GUIGARD, J. (1870-1873) Armorial du Bibliophile, tomo I, París, pp.165-167. 
En 1728 se publicó un catálogo en tres volúmenes con 18.219 volúmenes divididos en cinco grandes materias: Teología 3.738 volúmenes, Jurisprudencia 2.563 volúmenes, Historia 6.079 volúmenes, Ciencias y Artes 2.829 volúmenes y Bellas Artes 2.999 volúmenes; la primera parte del catálogo contenía los libros in folio (1-4.190 vol.); la segunda parte contenía los libros in cuarto (4.191-11.855 vol.); y la tercera los libros in 8. in 12 (11.856-18.219 vol.).

Los libreros parisinos intentaron detener la venta pero no fue posible. La Biblioteca Real adquirió la mayor parte del fondo, aunque Carlo Pertusatti, Conde de Castelferro, bibliófilo y presidente del senado de Milán, se hizo también con un grupo de obras, que pasó a formar parte de su rica biblioteca (de cerca de 24.000 volúmenes), que fue adquirida por la Congregazione di Stato di Milano (1763), siendo el fondo reconocido como de uso público por la emperatriz María Teresa de Austria (1770), transfiriéndose al Palazzo del Colegio de Brera, y junto a los fondos de la suprimida Compañía de Jesús, formó el núcleo de la famosa Biblioteca Braidense de Milán.

Los jesuitas también adquirieron algunas obras específicas para incorporarlas a algunas de sus bibliotecas, llegando parte de esos volúmenes al Colegio Imperial de Madrid antes de 1767. En 1845 la biblioteca de los jesuitas pasó a la de la Universidad madrileña, siendo actualmente uno de los fondos más importantes de la Biblioteca Histórica de la Universidad Complutense. Otros ejemplares terminaron en la Biblioteca de los Duques de Osuna, que tras la quiebra de la Casa fue vendida en almoneda, llegando parte de los fondos a varias universidades, como podemos ver en esta encuadernación con dos superlibros, el del Abad Colbert y el del Duque de Osuna, perteneciente a la Universidad de Salamanca 9 .

En la biblioteca de Colbert trabajó como encuadernador Éloy Le Vasseur, como queda anotado en los libros de registro de Pierre de Carcavy y Étienne Baluze, quienes estaban al cuidado de la Biblioteca Colbertina. También aparecen en los registros en nombre del encuadernador Bernard Picart. Como grabador de los anagramas heráldicos aparece Simon Tomassin. En los libros de registro de la biblioteca se han podido encontrar los precios de las encuadernaciones en la época de Jean-Baptiste: ocho libras por un gran folio, cuatro libras por un tamaño folio, dos libras de un tamaño cuarto y una libra por un tamaño octavo. En una memoria conservada actualmente en la Biblioteca Real aparece una anotación donde se indica el empleo de 4.140 pieles de marroquín para la encuadernación de 9.120 obras de la Biblioteca, algo habitual ya que Colbert era muy riguroso con la política de encuadernaciones para la protección de sus obras.

9 BG 4436/4437. Sancti Agobardi archiepiscopi Lugdunensis Opera. Item epistolae et opuscula Leidradi et Amulonis archiepiscoporum Lugdunensium. Stephanus Baluzius Tutelensis in unum collegit, emendavit, notisque illustravit, París, dos volúmenes, 1665-1666. 


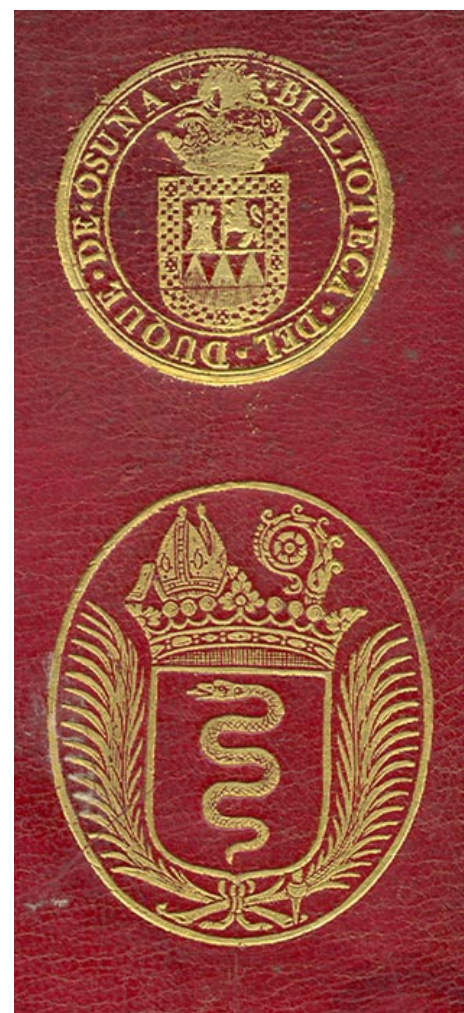

Figura 1. Superlibris del Duque de Osuna y del Abad Colbert

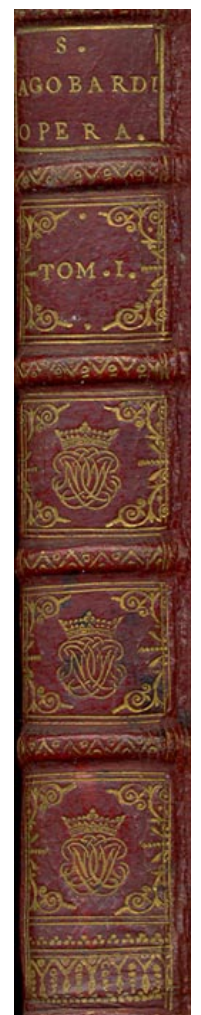

Figura 2. Lomo (sig. BG 4436/4437) de la Universidad de Salamanca

Como podremos observar todas las encuadernaciones de la familia Colbert depositadas en la Biblioteca Complutense pertenecen a eclesiásticos, ya que contienen elementos como los capelos episcopales por timbre, junto a báculos y mitras. De entre los miembros de esta extensa familia que se dedicaron a la Iglesia en la segunda mitad del XVII, podemos destacar a:

- Nicolas Colbert (1627-1676), Obispo de Luçon (1661-1671) y después de Auxerre (1671-1676).

- Michel Colbert de Saint-Pouange (1629-1676), Obispo de Mâcon (16661676).

- Jacques Baptiste Michel Colbert de Villacerf de Saint-Pouange (1640-1710), Obispo de Montauban (1675-1693) y Arzobispo de Toulouse (1693-1710).

- André Colbert (1648-1704), Obispo de Auxerre (1678-1704).

- Jacques-Nicolas Colbert (1655-1707), Arzobispo de Cartago y Coadjutor de Rouen (1680-1691) y Arzobispo de Rouen (1691-1707).

- Charles-Joachim de Colbert de Croissy (1667-1738), Obispo de Montpellier (1697-1738). 
Uno de los primeros detalles que llama la atención de estas encuadernaciones es la similitud en la decoración de las tapas, simplemente decoradas con el escudo de

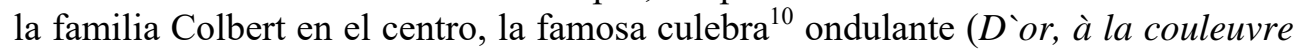
d'azur, ondoyante en pal) algunos de ellos con un encuadramiento formado por tres filetes dorados. Donde aparecen más diferencias es en la decoración de los entrenervios con una $\mathrm{J}$ y $\mathrm{C}$ entrelazadas junto a una corona de marqués, un florón con forma romboidal, o una culebra siendo los tres elementos decorativos de la parte central de los entrenervios. También existen diferentes tipos de ruedas que decoran los cantos así como guardas, algunas sin decoración y otras con diseños marmoleados de tipo caracolas, peine, etc.

Pasemos ahora a estudiar las encuadernaciones colbertianas de la Biblioteca Complutense, pero antes mostraremos la encuadernación tipo que utilizó el fundador de la Biblioteca, el Gran Colbert, que muestra el escudo con las armas familiares (la culebra), sumadas por la corona de marqués ${ }^{11}$, y rodeada de los collares de las órdenes de San Miguel y del Espíritu Santo (fue Gran Tesorero de las órdenes del Rey desde 1665 a 1675, manteniéndose este cargo en la familia Colbert hasta 1706), siendo los hierros de este superlibris realizados en 1672 por Simon Thomassin. En los entrenervios de estas obras aparece una cifra compuesta por las letras iniciales del nombre y apellido del propietario, JBC, entrelazadas y bajo corona de marqués, siempre acompañados de las culebras heráldicas de la familia.
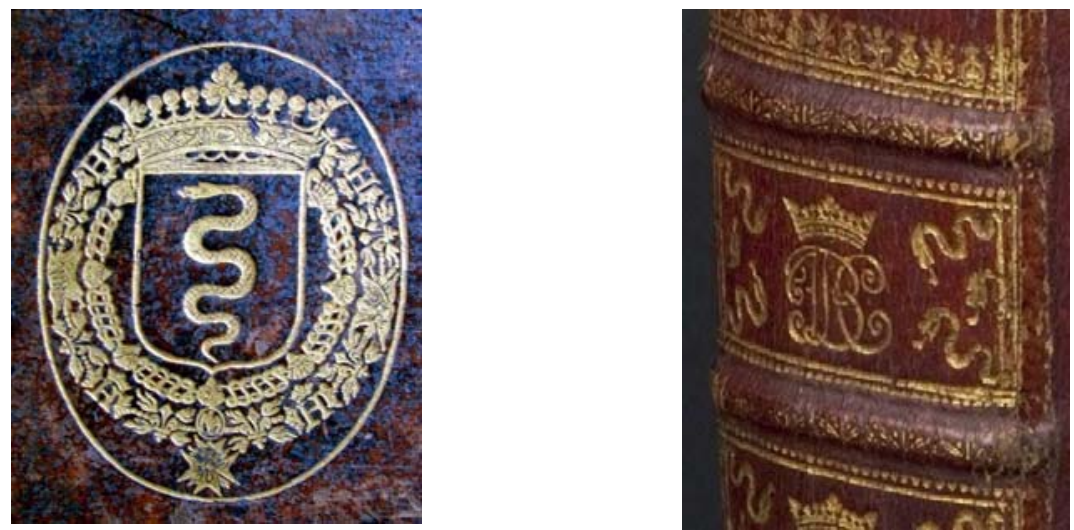

Figuras 3 y 4. Escudo de Jean Baptiste Colbert, Marqués de Seignelay, el conocido como Gran Colbert, con la corona de marqués y rodeado con los collares de las Órdenes de San Miguel y Espíritu Santo, y sus iniciales coronadas en los entrenervios

Sobre las encuadernaciones heráldicas debemos decir que nos aportan mucha información: en primer lugar identifican a la familia del propietario, y luego los ornamentos exteriores dan información sobre los cargos y honores que ha tenido el

10 Mantenemos este término, aunque en castellano la denominación heráldica correcta es la de sierpe.

11 En este trabajo vamos a ver dos modelos de esta Corona, la que se ve en esta encuadernación, con seis perlas colocadas a la misma altura a los lados del florón central; y el segundo donde dichas perlas se unen formando un triángulo de tres perlas cada una, haciendo una forma similar al florón central. 
personaje concreto, pudiendo así hacer un seguimiento de su cursus honorum, como veremos en el caso del Arzobispo de Rouen. Ahora bien los usos heráldicos son complejos, sólo en documentos oficiales suelen aparecer todos los símbolos que un individuo ha ido adquiriendo en su vida, como por ejemplo en sus sellos de cargo, pero en los usos privados, como el caso de las encuadernaciones, a veces se mantienen modelos de superlibros durante mucho tiempo sin introducirle los cambios que en teoría debían tener, lo cual se une a los deseos de los personajes concretos que ocupan un cargo oficial que conlleva heráldica propia, como es el caso de los eclesiásticos. Por ejemplo, el obispo de Montpellier era también conde de Melgueil, y por tanto sus armas van timbradas por una corona de conde, pero muchos de los obispos no la usan o bien usan otras, en el caso de Charles Joaquim Colbert de Croissy, que usa la de marqués propia de su familia; un caso similar ocurre con los arzobispos de Rouen, que utilizan en sus armas la corona ducal, pero algunos de los prelados usan otros timbres, la mayor parte ligados a sus orígenes familiares. Por todo ello la identificación de los escudos es a veces muy complicada, así como su datación, y la mejor manera de identificarlos es buscar alguno igual unido a una fecha concreta que no ofrezca dudas, como publicaciones del mismo prelado fechadas, documentos con sello, etc.

\section{Encuadernaciones de Jacques-Nicolas Colbert (1655-1707), Abad de Bec- Hellouin, Arzobispo titular de Cartago, coadjutor y luego Arzobispo de Rouen}

Las encuadernaciones con tipos heráldicos que suelen atribuirse a Jacques Nicolas Colbert son cuatro, la primera es de su época de abad (a partir de 1664) (fig. 5), la segunda muestra su ascenso al episcopado como arzobispo titular de Cartago (1680) (fig. 6) y coadjutor del arzobispado de Rouen, época a la que pertenece también la tercera (fig. 7), que muestra un diseño distinto de la corona de marqués que aparece también en la primera. La cuarta (fig. 8) es la de Arzobispo de Rouen, que conllevaba el primado de Normandía, que se distingue por la aparición de la cruz de doble travesaño bajo el capelo, en este caso con quince borlas, y la desaparición de los símbolos abaciales, presentes en todas las anteriores.

Veamos ahora los tipos presentes en la Biblioteca Complutense y sus especificidades. La primera serie de encuadernaciones está formada por seis volúmenes donde se incluyen obras impresas entre 1614 y 1692. Contienen en el centro de las dos tapas el superlibris de Jacques-Nicolas Colbert dentro de un óvalo. Los superlibris son similares aunque contienen pequeñas diferencias en la parte inferior de las palmas. Este grupo seguramente fue encuadernado entre 1664 cuando fue ordenado Abad de Bec-Hellouin - y 1691, - cuando tomó posesión del Arzobispado de Rouen - aunque al menos uno de los volúmenes (DER 3768) pudiera ser encuadernado en 1692 con el mismo anagrama aunque ya fuera Arzobispo. 


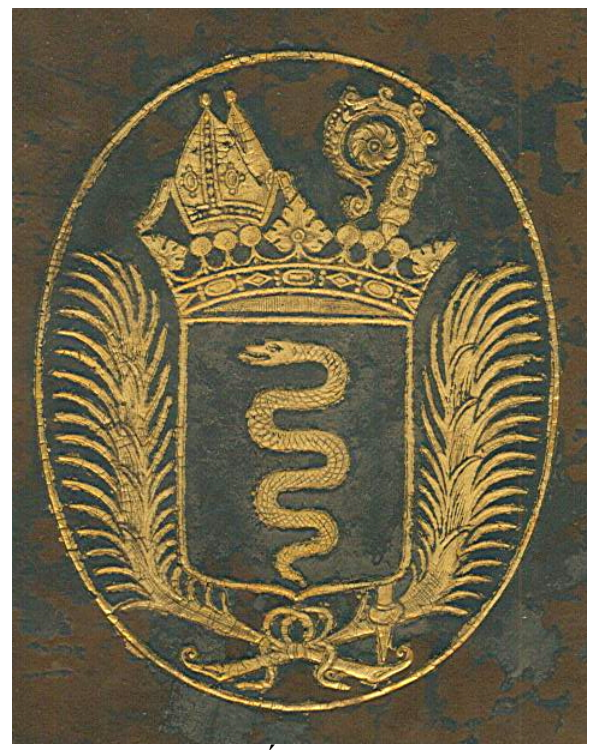

Figura 5. Época de Abad

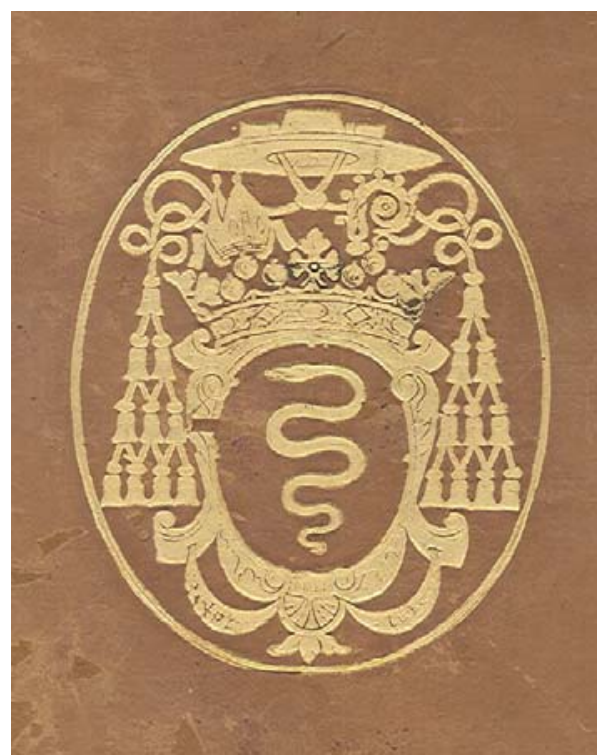

Figura 7. Arzobispo titular de Cartago

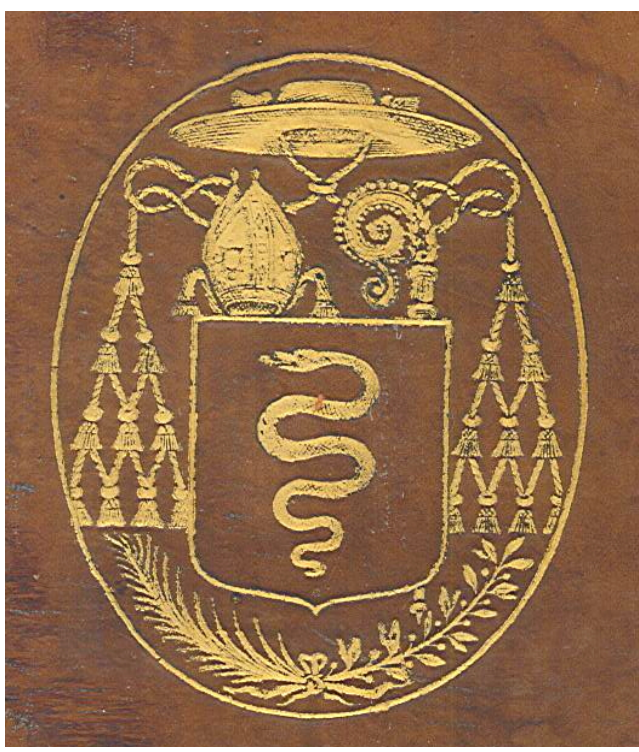

Figura 6. Arzobispo titular de Cartago

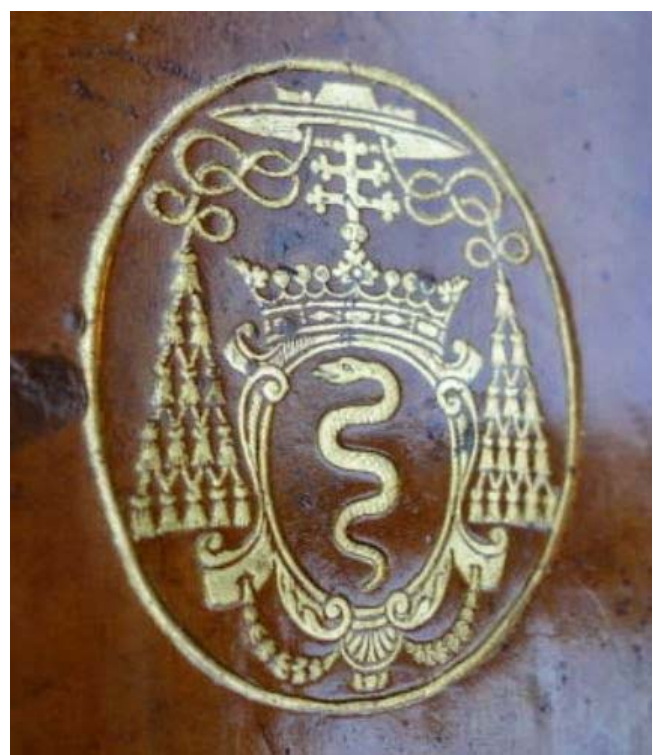

Figura 8. Arzobispo de Rouen 


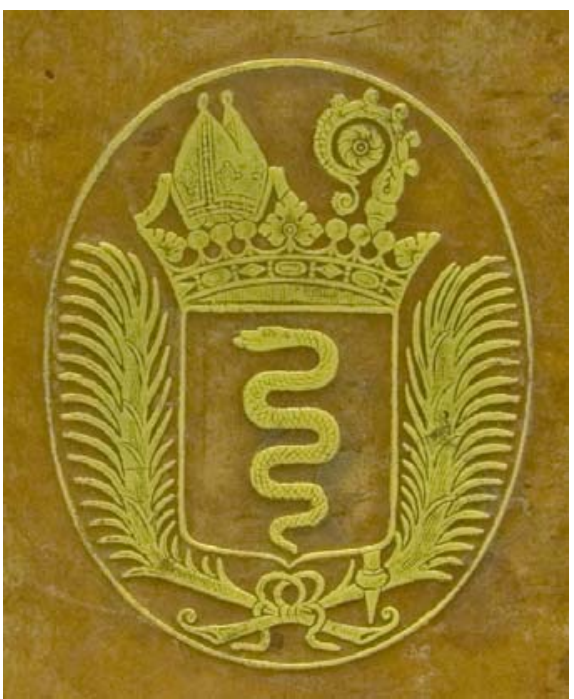

Figura 9. Sig. DER 4173

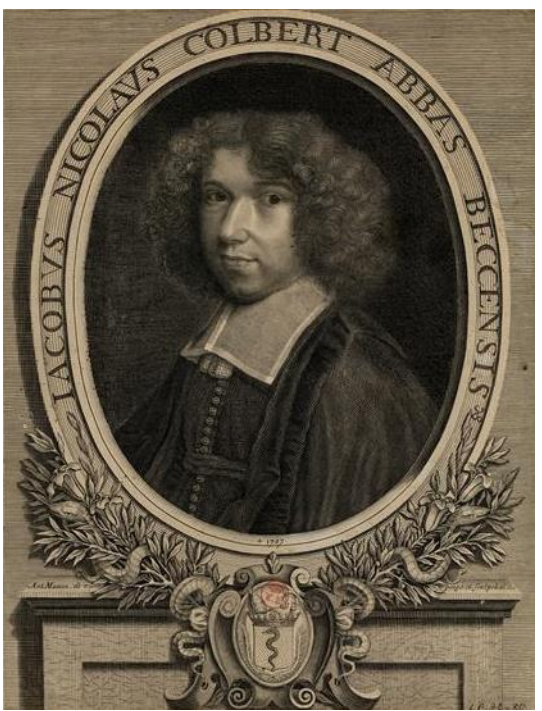

Figuras 11 y 12. Grabados del prelado en su época de Abad de Bec-Hellouin y de Arzobispo de Rouen con distintos ornamentos y mostrando su escudo oficial

Jacques-Nicolas Colbert, segundo hijo del Gran Colbert nació en París el 14 de febrero de 1655 y murió en esa misma ciudad el 10 de diciembre de 1707, siendo enterrado en la iglesia de Saint-Eustache. Desde joven se le encaminó a la Iglesia y a una edad muy temprana recibió la Abadía de Bec-Hellouin (1664) y otros beneficios, antes de ordenarse sacerdote ( 6 de abril de 1679). Poco después fue elegido coadjutor del Arzobispado de Rouen ( 2 de febrero de 1680), siendo confirmado en el cargo y 
nombrado arzobispo titular de Cartago el 29 de abril de 1680, lo que le llevó a ser ordenado obispo el 4 de agosto de 1680. Sucedió en el Arzobispado de Rouen el 29 de enero de 1691 al fallecido François Rouxel de Médavy.

El escudo que contiene la pequeña variante decora el volumen con la obra de Isaac Casaubon (1559-1614) titulada Isaaci Casauboni de rebus sacris et ecclesiasticis exercitationes XVI : ad Cardinalis Baronii prolegomena in Annales et primam eorum partem de Domini Nostri Iesu Christi Natiuitate, Vita, Passione, Assumtione ..., impresa en Londres en 1614, con signatura DER 4173. Sus dimensiones son 300 X 208 X $58 \mathrm{~mm}$. Ingresó en la Biblioteca Histórica procedente de la Biblioteca de la Facultad de Derecho en $2000^{12}$.

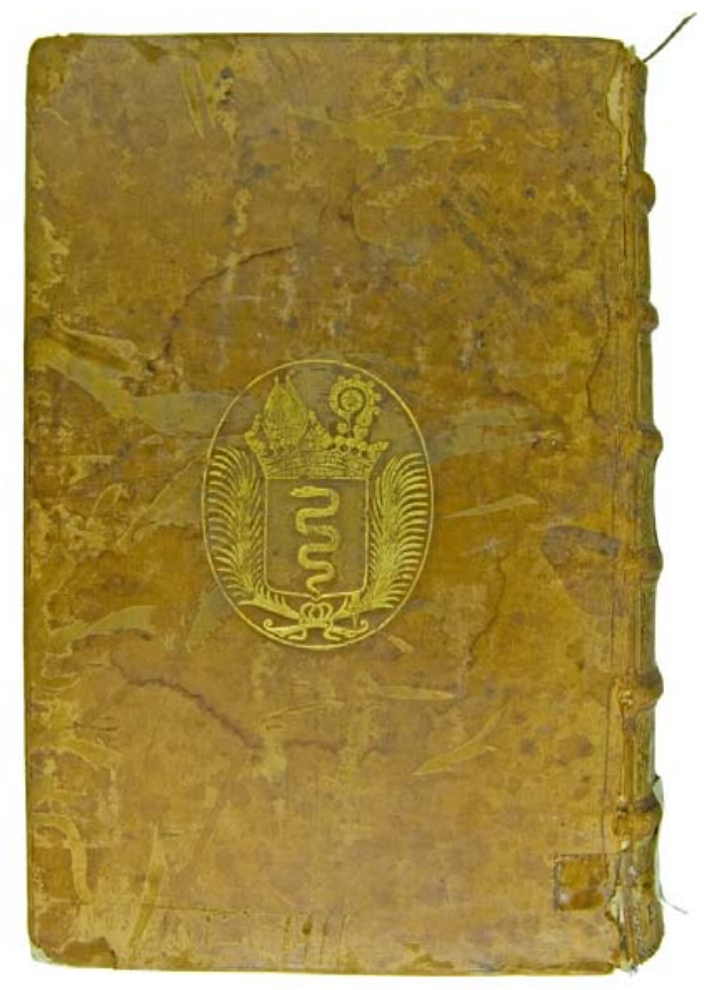

Figura 13. Sig. DER 4173

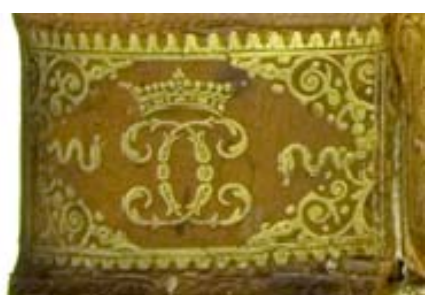

Figura 14. Entrenervio

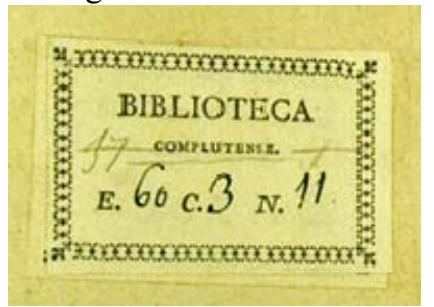

Figura 15. Exlibris de la guarda

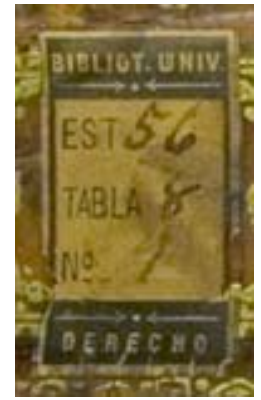

Figura 16. Tejuelo del lomo

Las tapas son de cartón recubierto de piel de becerro color avellana, al igual que el lomo, las guardas y las hojas de respeto son de papel verjurado crema, los nervios

12 En las primeras hojas de la obra aparecen diversas inscripciones manuscritas que detallamos a continuación: Exlibris manuscrito de Cl. Christiani Q.[uintis] Frorentis f.[ilii]. Exlibris de la Biblioteca Complutense. Anotación ms. En la hoja de guardas: Autor damnatus opus vero permisum. Ex comisione Generalis Inquisitores. Dris. Santus Llama. (Información extraída de la nota del registro bibliográfico). 
son de tiras de piel, los cortes están decorados con tinta marrón y roja, el núcleo de las cabezadas es de tiras de piel recubierto de hilos de colores rojo y azul.

Las tapas están encartonadas mediante seis nervios dobles, el lomo está redondeado, las cabezadas están realizadas manualmente y unidas a los cuadernillos y a las tapas, los cortes están decorados mediante la técnica del estarcido.

La estructura de la tapa es simétrica con un óvalo dorado en el centro de las tapas en cuyo interior aparece el superlibris de Jacques-Nicolas Colbert. El escudo abacial trae en el campo una culebra en el centro (palo); (al timbre) rodeado por los emblemas del báculo y la mitra, y una corona de marqués; a diestra y siniestra aparecen dos hojas de palma. El utensilio empleado ha sido la plancha y la técnica de decoración el dorado. Los entrenervios están formados por un encuadramiento de un filete y dientes de ratón festoneados hacia el exterior en las bandas horizontales y dos filetes en las bandas verticales; en las esquinas aparece una decoración floral, en los lados unas pequeñas culebras y en el centro una $\mathrm{J}$ y una $\mathrm{C}$ entrelazadas, de (J)acques-Nicolas (C)olbert y la corona de marqués ${ }^{13}$. El tejuelo está decorado con el mismo encuadramiento que el resto de los entrenervios con la leyenda dorada "CASAVBONI / EXERCITAT / IN ANNAL / G BAPOII". La cabezada está decorada con el alternado de hilo de colores rojo y verde. Los cortes están decorados con gotas de color rojo y marrón.

Las tapas contienen numerosas rozaduras y pérdidas de piel en las esquinas. La piel que une las tapas con el lomo está totalmente deteriorada. Los nervios han perdido parte de su decoración debido a las rozaduras. Los entrenervios superior e inferior han perdido parte de la piel y han dejado al descubierto las cabezadas. Los entrenervios contienen pequeñas grietas y manchas. Las cabezadas prácticamente han desaparecido. El cosido, los cortes, las guardas y las hojas de respeto están en buen estado.

En el lomo aparece un tejuelo de la Facultad de Derecho con la información EST 56 - TABLA 8 - $\mathrm{N}^{\mathrm{o}}$ 9; en la guarda anterior aparece un exlibris de la Biblioteca Complutense con la signatura E. 60 - C. 3 - N. 11, lo que nos indica la trayectoria de este volumen dentro de la institución.

Los otros cinco volúmenes de esta primera serie contienen el mismo superlibris en el centro de las tapas, junto al anagrama en el centro de los entrenervios con una $\mathrm{J}$ y una $\mathrm{C}$ entrelazadas, de (J)acques-Nicolas (C)olbert y la corona de marqués, y pequeñas culebras a los lados, aunque la decoración de las esquinas es diferente.

El primero de ellos (DER 3768) contiene la obra de Jean Mabillon (O.S.B.) titulada Reflexions sur la réponse de M. l'Abbé de la Trappe au Traité des études monastiques, impresa en Paris en 1692; sus dimensiones son 263 X 200 X 30 $\mathrm{mm}$. Los siguientes dos volúmenes coinciden en la decoración de las esquinas de los entrenervios, así como en la rueda de motivos vegetales que decoran los cantos:

13 El uso en los entrenervios de las iniciales entrelazadas bajo corona de marqués y acompañadas de las culebras heráldicas será muy común en todas las encuadernaciones de los Colbert (lo vemos en las del II Marqués de Seignelay, en el Arzobispo de Rouen, en el Obispo de Montpeliier, etc.) 
el primero (DER 13764) ${ }^{14}$ contiene la obra de Jean Mabillon (O.S.B.) titulada Traité de études monastiques : divise en trois parties : avec une liste des principales difficutez qui se rencontrent en chaque siécle dans la lecture des Originaux, et un catalogue de libres choisis pour composer una Bibliotéque ecclesiastique, publicada en Paris en 1691; sus dimensiones son 257 X 186 X 31 $\mathrm{mm}$; el segundo volumen (DER 14173) ${ }^{15}$ contiene la obra Iter Italicum Litterarium, impresa entre 1685-1686; sus dimensiones son 252 X 189 X 23 mm.

Las tapas son de cartón recubierto de piel de becerro color avellana, al igual que el lomo, las guardas son de papel marmoleado de colores rojo, azul, amarillo y verde (DER 3768), en los otros dos volúmenes las guardas son de papel verjurado, las hojas de respeto son de papel verjurado crema, el tejuelo de piel es de color granate excepto el del volumen (DER 14173) que carece de tejuelo, los nervios son de tiras de piel, los cortes están pintados con tinta roja, el núcleo de la cabezada es doble de tiras de piel recubierto de hilos de color rojo (DER 3768).

Las tapas están encartonadas mediante un cosido con cinco nervios sencillos, aunque en el volumen DER 3768 tres cordeles están encartonados y dos sin encartonar, el lomo está redondeado y la cabezada, realizada manualmente, está unida a los cuadernillos (DER 3768).
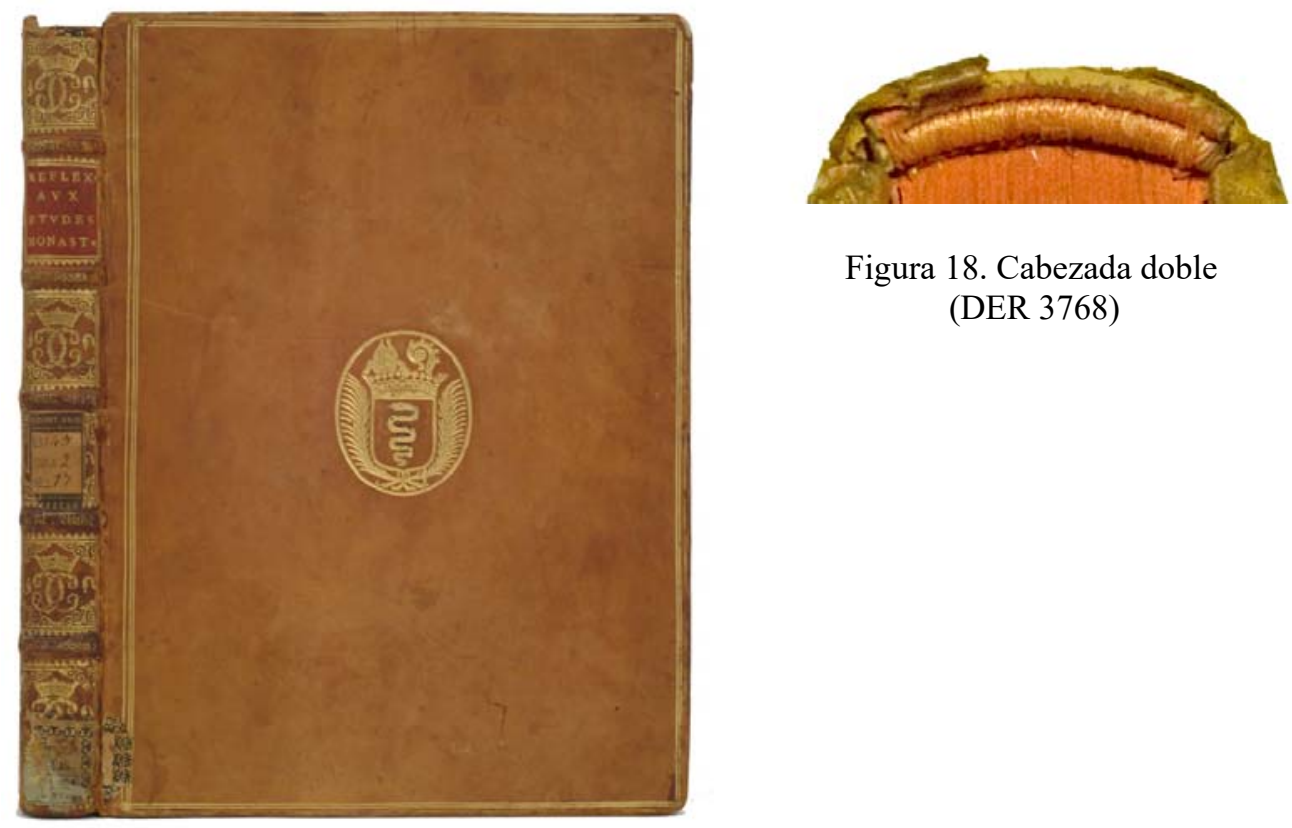

Figura 18. Cabezada doble (DER 3768)

Figura 17. Sig. DER 3768

14 En las primeras hojas de la obra aparecen diversas inscripciones manuscritas que detallamos a continuación: Ex dono authoris. Exlibris de la Biblioteca Complutense. (Información extraída de la nota del registro bibliográfico).

15 En las primeras hojas de la obra aparecen diversas inscripciones manuscritas que detallamos a continuación: Exlibris ms. De la Bibliotheca Complutensi Ildefonsina. Exlibris impreso, con signatura topográfica, de la Biblioteca Complutense. (Información extraída de la nota del registro bibliográfico). 


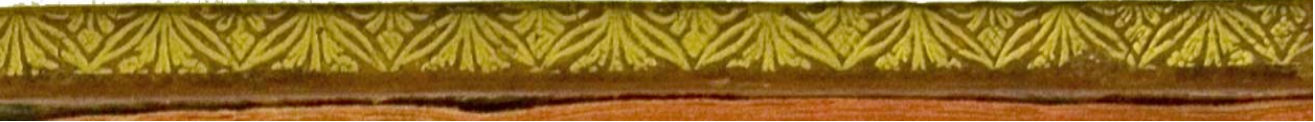

Figura 19. Canto - Rueda con motivos vegetales (DER 3768 / DER 13764 / DER 14173)

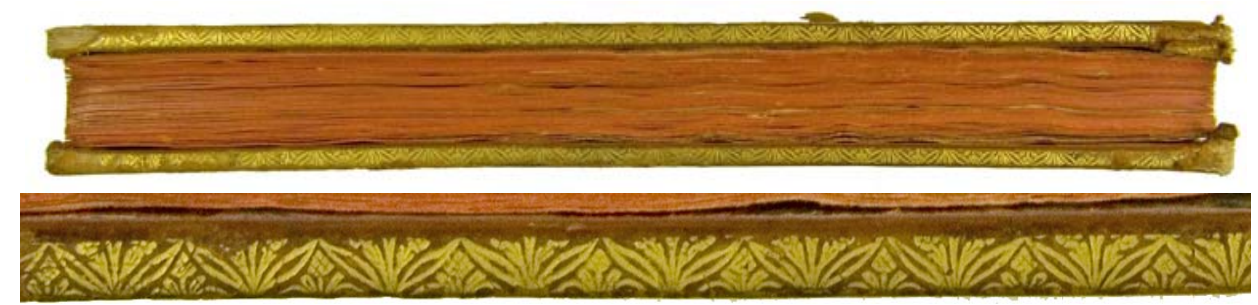

Figura 20. Corte pintado de color rojo (DER 14173)

La estructura de la tapa es simétrica. La decoración se inicia con un encuadramiento formado por tres hilos dorados, el exterior algo más separado, unidos en las esquinas por un motivo florar circular. En el centro de la tapa aparece el superlibris de Jacques-Nicolas Colbert. El escudo abacial trae en el campo una culebra en el centro (palo); (al timbre) rodeado por los emblemas del báculo y la mitra, y una corona de marqués; a diestra y siniestra aparecen dos hojas de palmas. El utensilio empleado ha sido la plancha y la técnica de decoración el dorado. Los cantos y los nervios están decorados con una misma una rueda de motivos vegetales. Los entrenervios están decorados con un encuadramiento formado por un filete y motivos dentados festoneados hacia el exterior en las bandas horizontales y por dos filetes en las bandas verticales; en las esquinas aparece una decoración floral que tiene pequeñas variantes en los tres volúmenes, en los lados unas pequeñas culebras y en el centro una $\mathrm{J}$ y una $\mathrm{C}$ entrelazadas, de (J)acquesNicolas (C)olbert y la corona de marqués, todo ello dorado. Los tejuelos están decorados con el mismo encuadramiento que el resto de los entrenervios y con las leyendas "REFLEX / AVX / ETVDES / MONAST" (DER 3768), “TRAITÈ / DES / ETVDES / MONAST” (DER 13764), y “ITRE / ITALI / CVM” (DER 14173), todo ello dorado. La cabezada (DER 3768) está decorada con hilo de color rojo. Los cortes están coloreados y bruñidos con tinta roja. El papel de las guardas del volumen con sig. DER 3768 es blanco y está marmoleado mediante el traspaso por contacto de la pintura y decoración realizada en la superficie de un líquido mucilaginoso contenido en una cubeta. Se han empleado acuarelas de color rojo, azul, verde y amarillo y una lluvia de agua de hiel que deja aparecer el color de fondo del papel en forma de pequeños puntos blancos. Este modelo forma parte de un grupo que puede denominarse mixto, pues aunque el fondo es un modelo de gotas o mármoles, estas no quedan sin manipular sino que se realiza sobre ellas un movimiento en espiral, con un punzón o con un peine, para disponerlas aisladamente o bien en series colocadas a intervalos regulares. 


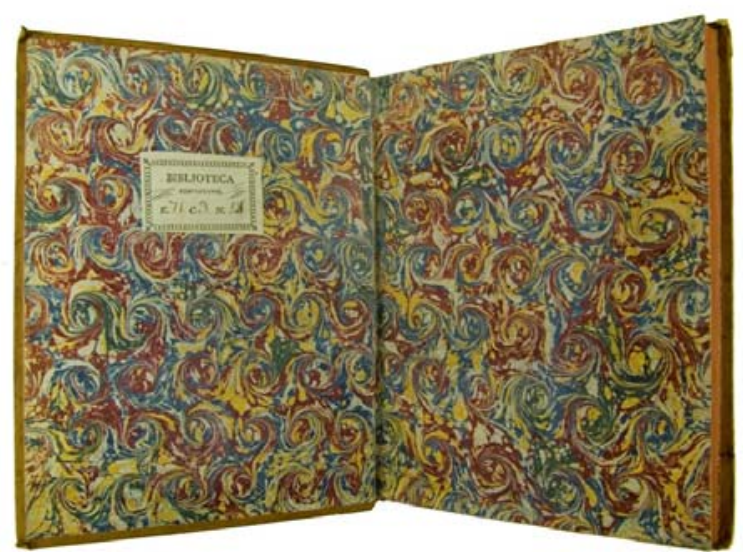

Figura 21. Guarda anterior marmoleada (DER 3768)

Como en el primer volumen de esta serie, en los lomos y guardas aparecen tejuelos y exlibris que nos indican el camino que han tenido los ejemplares en la Biblioteca Complutense. La información que nos ofrecen estos tres volúmenes es la siguiente:

\begin{tabular}{|l|c|c|}
\hline & Bib. de la Fac. de Derecho & Biblioteca Complutense \\
\hline DER 3768 & EST $45-$ TABLA $2-\mathrm{N}^{\circ} 17$ & E. $71-$ C. $3-$ N. 14 \\
\hline DER 13764 & EST $35-$ TABLA $7-\mathrm{N}^{\text {o } 19}$ & E. $71-$ C. $3-$ N. 12 \\
\hline DER 14173 & EST $10-$ TABLA $7-\mathrm{N}^{\circ} 4$ & E. $70-$ C. $6-$ N. 8 \\
\hline
\end{tabular}

Las tapas de los tres volúmenes presentan diversas rozaduras y pérdidas de piel en las esquinas, junto a algunas manchas. La tapa anterior contiene pequeñas roturas de piel cerca del lomo (DER 3768); la piel que une las tapas con el lomo está totalmente deteriorada (DER 14173 y DER 13764). Los nervios han perdido parte de su decoración debido a las rozaduras. Las cofias han perdido parte de la piel y han dejado al descubierto la cabezada. Los entrenervios contienen pequeñas grietas y manchas. Las cabezadas han desaparecido a excepción de la cabezada inferior del volumen DER 3768. Las guardas están en buen estado aunque algo descoloridas y deterioradas en la zona de la bisagra. El cosido, los cortes, las hojas de respeto y los tejuelos están en buen estado.

Los dos últimos volúmenes de esta serie comparten emblema central en las tapas y decoración en los entrenervios, cantos y cortes. El primero (DER 14298) ${ }^{16}$ contiene la obra titulada Analecta Graeca sive Varia opuscula Graeca hactenus non edita / ex Mss. Codicibus erverunt, latine verterunt, \& notis illustrarunt Monachi Benedictini, Congregationis Sancti Mauri ; tomus primus, impresa en París en 1688; sus dimensiones son 252 X 200 X 35 mm. El segundo (DER

16 En las primeras hojas de la obra aparecen diversas inscripciones manuscritas que detallamos a continuación: Exlibris del Colegio Mayor de San Ildefonso de la Universidad de Alcalá. Ingreso en la Biblioteca Histórica procedente de la Facultad de Derecho en 2000. (Información extraída de la nota del registro bibliográfico). 
$16298)^{17}$ contiene la obra de Silvestros Syropoulos (ca. 1401-ca. 1464) titulada Vera historia unionis non verae inter graecos et latinos : siue Concilii Florentini exactissima narratio, graecè scripta per Sylvestrum Sguropulum ... transtulit in sermonem latinum ... Robertus Creghton ..., impresa en Hagae-Comitis (La Haya) por Adriani Vlacq en 1660; sus dimensiones son 298 X 198 X 39 mm.

Las tapas son de cartón recubierto de piel de becerro color avellanada al igual que el lomo, las guardas y hojas de respeto de papel verjurado crema, los nervios son de tiras de piel, el tejuelo es de piel granate, los cortes están decorados con tinta roja, el núcleo de las cabezadas inferiores es doble de tira de piel recubierto de hilo de color rojo.

Las tapas están encartonadas mediante cinco nervios sencillos, el lomo es redondeado, las cabezadas, realizadas manualmente, están unidas a los cuadernillos.

La estructura de la tapa es simétrica. La decoración se inicia con un encuadramiento formado por tres hilos dorados, el exterior algo más separado, unidos en las esquinas por un motivo florar circular. En el centro de la tapa aparece el superlibris de Jacques-Nicolas Colbert. El escudo abacial trae en el campo una culebra en el centro (palo); (al timbre) rodeado por los emblemas del báculo y la mitra, y una corona de marqués; a diestra y siniestra aparecen dos hojas de palmas. El utensilio empleado ha sido la plancha y la técnica de decoración el dorado. Los nervios (DER 16298) están decorados con una paleta dorada con motivos vegetales estilizados similar a la rueda empleada para la decoración de los cantos de los volúmenes DER 3768, DER 13764 y DER 14173; los nervios del volumen DER 14298 están decorados con una paleta dorada de diferentes motivos vegetales. Los cantos de ambos volúmenes están decorados con una rueda dorada que contiene tres tipos de flores de ocho pétalos. Los entrenervios están decorados con un encuadramiento formado por un filete y motivos dentados festoneados hacia el exterior en las bandas horizontales y por dos filetes en las bandas verticales; en las esquinas aparece una decoración floral, en los lados unas pequeñas culebras y en el centro una $\mathrm{J}$ y una $\mathrm{C}$ entrelazadas, de (J)acques-Nicolas (C)olbert y la corona de marqués, todo ello dorado. Los tejuelos están decorados con el mismo encuadramiento que el resto de los entrenervios y con las leyendas "ANALECTA / GRAECA" (DER 14298) y "HISTORIA / CONCIL / FLOREN" (DER 16298), todo ello dorado. Las cabezadas inferiores están decoradas con hilo de color rojo. Los cortes están coloreados con tinta roja.

17 En las primeras hojas de la obra aparecen diversas inscripciones manuscritas que detallamos a continuación: Exlibris de la Biblioteca Complutense. Ingreso en la Biblioteca Histórica procedente de la Facultad de Derecho en 2000. (Información extraída de la nota del registro bibliográfico). 


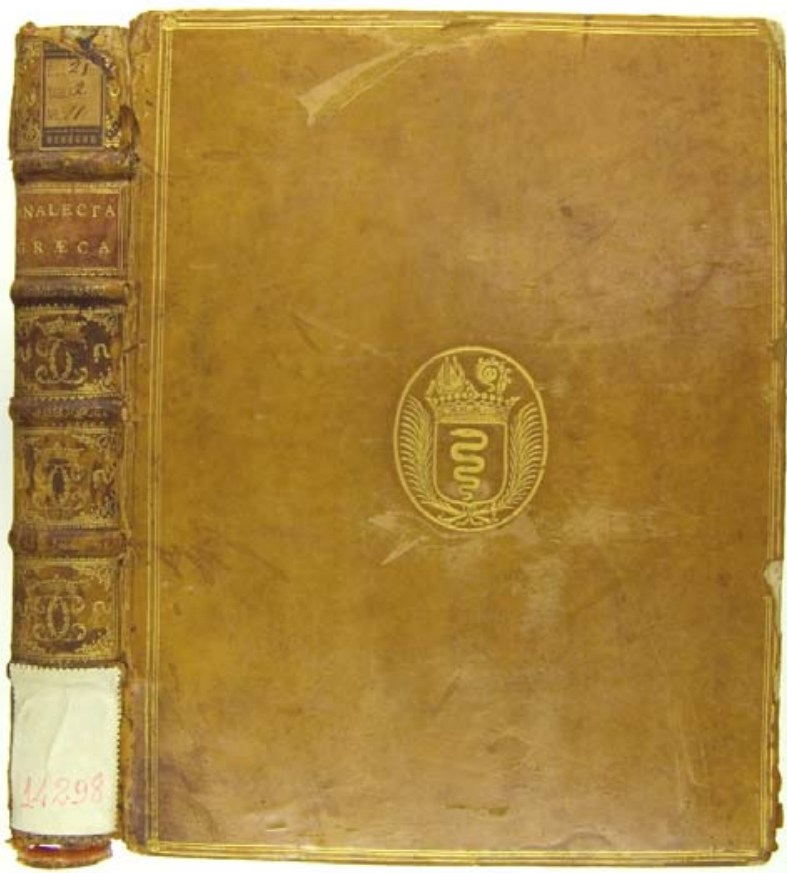

Figura 22. Sig. DER 14298

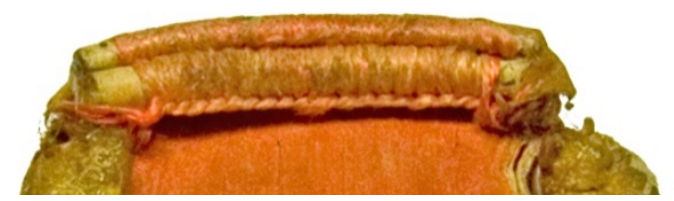

Figura 23. Cabezada doble (DER 14298)

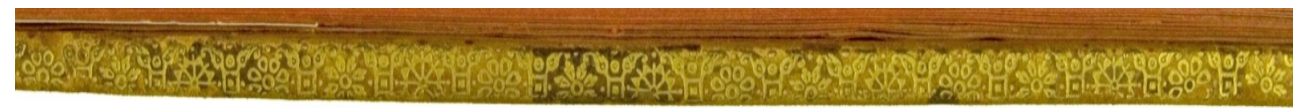

Figura 24. Detalle de los motivos florales de los cantos

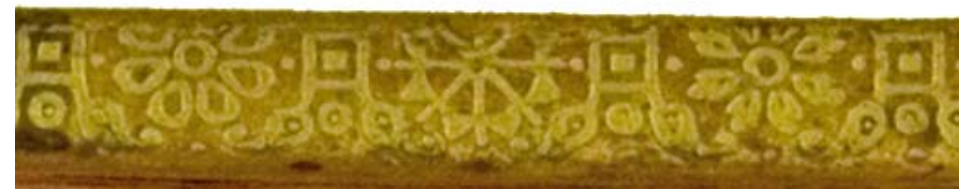

Figura 25. Canto - Rueda con motivos florales (DER 14298 y DER 16298) 


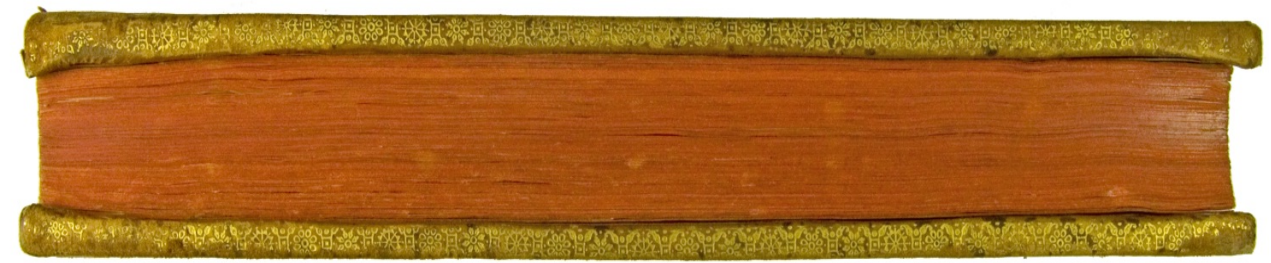

Figura 26. Corte pintado de color rojo (DER 16298)

Las tapas presentan diversas rozaduras y pérdidas de piel en las esquinas. La piel que une la tapa anterior con el lomo está totalmente deteriorada. Los nervios han perdido parte de su decoración debido a las rozaduras. Los entrenervios tienen pequeñas grietas y manchas. Las cofias han perdido parte de la piel y han dejado al descubierto las cabezadas inferiores. Las cabezadas superiores han desaparecido. Las guardas están en buen estado aunque algo sucias. Los tejuelos han perdido algo su coloración. El cosido, los cortes y las hojas de respeto están en buen estado.

Como en los volúmenes anteriores los exlibris y los tejuelos adheridos al lomo nos ofrecen datos sobre la historia de los ejemplares dentro de la Biblioteca Complutense.

\begin{tabular}{|l|c|c|}
\hline & Bib. de la Fac. de Derecho & Biblioteca Complutense \\
\hline DER 14298 & EST $21-$ TABLA $2-\mathrm{N}^{\circ} 11$ & E. $90-$ C. $7-$ N. 5 \\
\hline DER 16298 & EST $16-$ TABLA $5-\mathrm{N}^{\circ} 10$ & E. $42-$ C. $12-$ N. 10 \\
\hline
\end{tabular}

Como hemos comentado con anterioridad las principales variantes entre los seis volúmenes de esta serie, que contienen el superlibris de Jacques-Nicolas Colbert, se muestra en los entrenervios, principalmente en la decoración que aparece en las esquinas, aunque los seis volúmenes fueron realizados por el mismo encuadernador a primeros de la década de los noventa del siglo XVII en Francia.

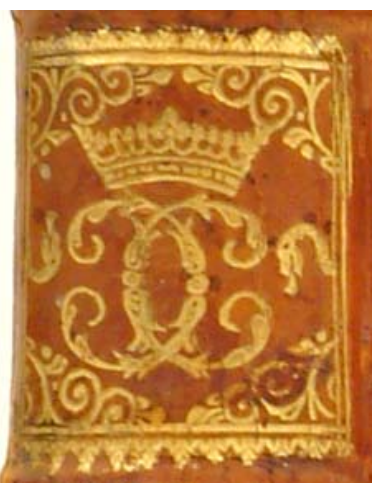

Figura 27. DER 3768

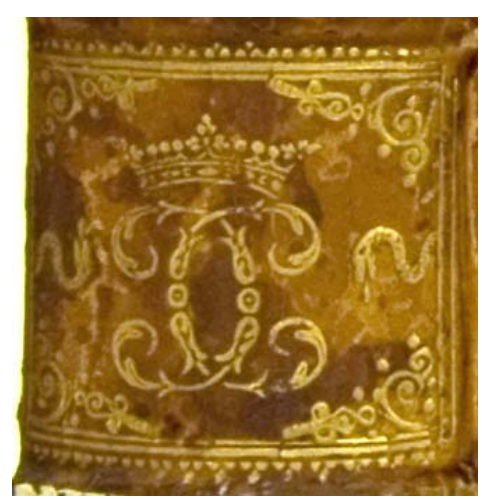

Figura 28. DER 14298 / DER 16289 / DER 4173 


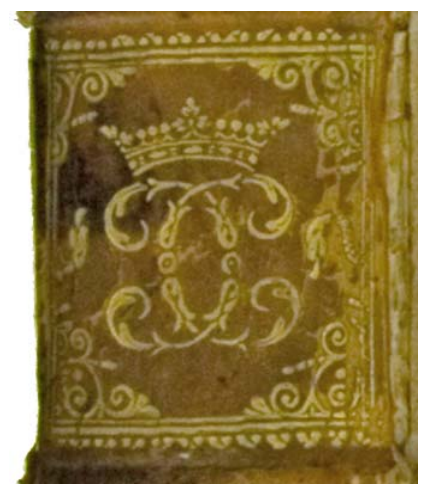

Figura 29. DER 13764 / DER 14173

La siguiente serie de este estudio está compuesto de un volumen (DER 3906) ${ }^{18}$ que contiene la obra de Leone Allacci con el título Vindiciae Synodi Ephesinae et S. Cyrilli de processione ex patre \& Filio Spirils Sancti. Romae : Typis Sac. Congreg. Propagandae Fidei, 1661, y sus dimensiones son 183 X 120 X 37 mm. La información que nos ofrecen los tejuelos es la siguiente:

\begin{tabular}{|c|c|}
\hline Bib. de la Fac. de Derecho & Biblioteca Complutense \\
\hline EST $48-$ TABLA $5-\mathrm{N}^{\circ} 19$ & E. $43-$ C. $18-$ N. 3 \\
\hline
\end{tabular}

Esta encuadernación fue realizada alrededor de 1692, fecha de la impresión de la obra y cuando Jacques-Nicolas Colbert ya había sido nombrado Arzobispo de Rouen, donde se mantiene la corona de marqués propia de su familia y los emblemas abaciales de la mitra y el báculo.

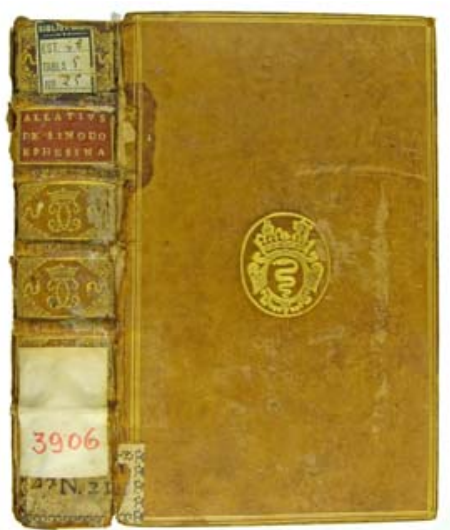

Figura 30. Sig. DER 3906

18 En las primeras hojas de la obra aparecen diversas inscripciones manuscritas que detallamos a continuación: En la guarda anterior aparece el exlibris de la Biblioteca Complutense; la obra ingresó en la Biblioteca Histórica procedente de la Biblioteca de la Facultad de Derecho en 2000. (Información extraída de la nota del registro bibliográfico). 

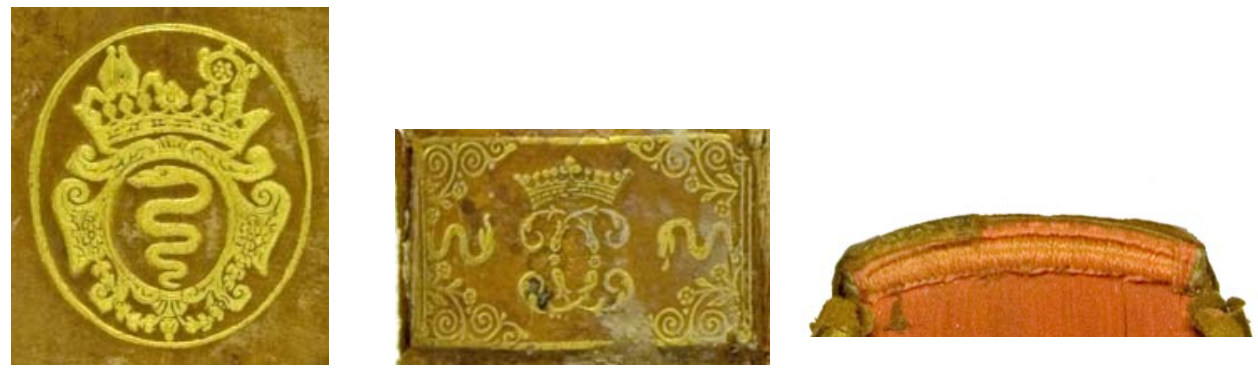

Figura 31. Escudo central Figura 32. Entrenervio

Figura 33. Cabezada inferior

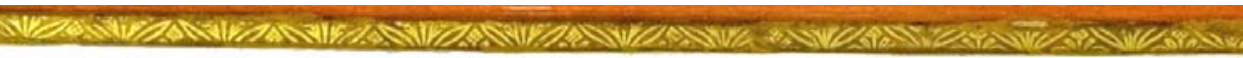

Figura 34. Canto decorado con una rueda de motivos vegetales

Las tapas son de cartón recubiertas de piel color avellana, al igual que el lomo, las guardas y las hojas de respeto son de papel verjurado crema, los nervios son de tiras de piel, el tejuelo es de piel granate, los cortes están decorados con tinta roja, el núcleo de la cabezada es de tira de piel recubierto de hilo de color rojo.

Las tapas están encartonadas mediante cinco nervios sencillos, el lomo es redondeado, la cabezada, realizada manualmente, está unida a los cuadernillos.

La estructura de la tapa es simétrica. La decoración se inicia con un encuadramiento formado por tres hilos lisos dorados. En el centro de la tapa aparece un óvalo dorado en cuyo interior hay un escudo de la familia Colbert, que trae en el campo una culebra en palo; (al timbre) sumada por los emblemas del báculo y la mitra, una corona de marqués. Los utensilios empleados han sido la plancha y la rueda y la técnica decorativa ha sido el dorado. Los cantos están dorados con una rueda y los nervios con una paleta de motivos vegetales. Los entrenervios están decorados con un encuadramiento formado por dos filetes en las bandas verticales y por un filete en las horizontales; la parte central está decorada con una $\mathrm{J}$ y una $\mathrm{C}$ entrelazadas, de (J)acques-Nicolas (C)olbert y la corona de marqués, todo ello dorado; a cada lado aparece una culebra dispuesta horizontalmente con motivos florales en las esquinas. El tejuelo está decorado con un encuadramiento formado por dos filetes en las bandas verticales y un filete en las bandas horizontales, con la leyenda "ALLATIVS / DE SINODO / EPHESINA", todo ello dorado. La cabezada está decorada con hilo de color rojo. Los cortes están coloreados y bruñidos con tinta roja.

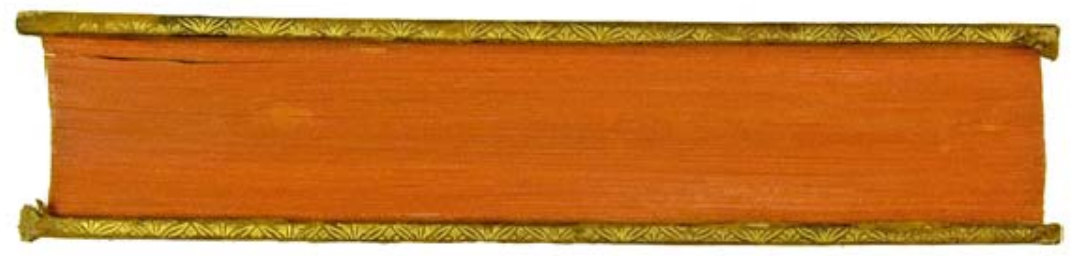

Figura 35. Corte pintado de color rojo 
Las tapas tienen numerosas rozaduras. La piel que une las tapas con el lomo está totalmente deteriorada. Los nervios han perdido parte de su decoración debido a las rozaduras. Los entrenervios tienen pequeñas grietas y manchas. Las cofias han perdido parte de la piel y han dejado al descubierto las cabezadas, las cuales prácticamente han desaparecido. Las guardas están en buen estado aunque algo sucias. El cosido, los cortes y las hojas de respeto están en buen estado.

A modo de epílogo y una vez realizado este estudio sobre las encuadernaciones de la familia Colbert, podemos determinar que en la Biblioteca Histórica de la Universidad Complutense están depositadas encuadernaciones de las dos ramas de los Colbert, una la de Jacques Nicolas Colbert, Arzobispo de Rouen, y la otra la de Charles Joachim Colbert de Croissy, Obispo de Montpellier. Con el presente artículo se ha determinado cuales obras pertenecieron a Jacques Nicolas Colbert, así como que fueron encuadernadas entre 1664, cuando fue ordenado Abad de BecHellouin, y 1691, cuando tomó posesión del Arzobispado de Rouen, aunque al menos uno de los volúmenes pudo haber sido encuadernado en 1692 con el mismo anagrama siendo ya Arzobispo, manteniéndose la corona de marqués propia de su familia y los emblemas abaciales de la mitra y el báculo. También podemos determinar, que una vez estudiados los elementos decorativos y de propiedad (ruedas, florones, superlibris, etc.), y comparados con otros ejemplares similares, las encuadernaciones fueron realizadas en el mismo taller. Todo ello nos ha ayudado a contribuir en la reconstrucción de la biblioteca de este bibliófilo francés de la segunda mitad del siglo XVII y primeros del XVIII.

\section{Referencias Bibliográficas}

Bibliotheca Colbertina. (1727). Parisiis: Gabrielem Martin y Franciscum Montalant.

Bloch, D. (1989-1992). La bibliothèque de Colbert. Oliver, B. W y Anghelescu, H. G. B. Histoire des bibliothèques françaises. Paris: Promodis-Editions du Cercle de la Librairie, 157-175.

Carpallo Bautista, A. (2005) Encuadernaciones en la Biblioteca Complutense. Madrid: Servicio de Publicaciones de la UCM.

Carpallo Bautista, A., Francisco Olmos, J.M. de. (2016). Estudio de las encuadernaciones de Charles Joachim Colbert de Croissy depositadas en la Biblioteca Complutense. Revista General de Información y Documentación, 26(2), 523-553.

Carpallo Bautista, A., Velez Celemín, A. (2010). Los papeles decorados en las encuadernaciones del Archivo y Bibliotecas Capitulares de la Catedral de Toledo. Toledo: Cabildo de la Catedral: Instituto Teológico San Ildefonso: Diputación Provincial.

Le carte decorate della Raccolta Bertarelli. (1991). A cura di Alberto Milano, Elena Villani. Milano: A. Mondadori arte.

Catalogus librorum bibliothecae illustrississimi ac reverendissimi D.D. Caroli-Joachimi Colbert de Croissi episcopi Montispessulani (1740). [Francia?: s.n.], 2 T.

Collet, A. (1999). Bibliotecae Colbertinae: recherches sur quelques livres ayant appartenu à Jean Baptiste, Nicolas et Jacques-Nicolas Colbert". Des livres et des hommes: 19891999. Saint-Étienne Cedex: Université, 155-162. 
Doizy, M. A. (1996). De la dominoterie à la marbrure. Paris: Art et métiers du livre/Editions.

Encyclopédie, ou dictionaire raisonné des sciences, etc. (1751-52). Ed. Diderot, D’Alambert. Paris: Le Breton, Vol. 10.

Guigard, J. (1870-1873). Armorial du Bibliophile, París: Emile Rondeau

Haemmerle, A. (1961). Buntpapier. Herkommen, Geschichte, Techniken, Beziehungen zurKunst. Münich: Georg D.W. Callwey.

Heijbroek, J. F. y Greven, T. C. (1994). Sierpapier, marmer-, brocaat- en sitspapier in Nederland. Amsterdam: De Buitenkant.

Olivier, E., Hermal, G. y Roton, R. de (1924-1938). Manuel de l'amateur de reliures armoriées françaises. Paris: Ch. Bosse, $30 \mathrm{~T}$.

Schmoller, T. (2008). To brighten things up: The Schmoller collection of decorated papers. Manchester: Manchester Metropolitan University.

Wolfe, R. J. (1990). Marbled Paper its History, Techniques, and Patterns. Philadelphia: University of Pennsylvania Press.

\section{Cuadro resumido de la familia Colbert}

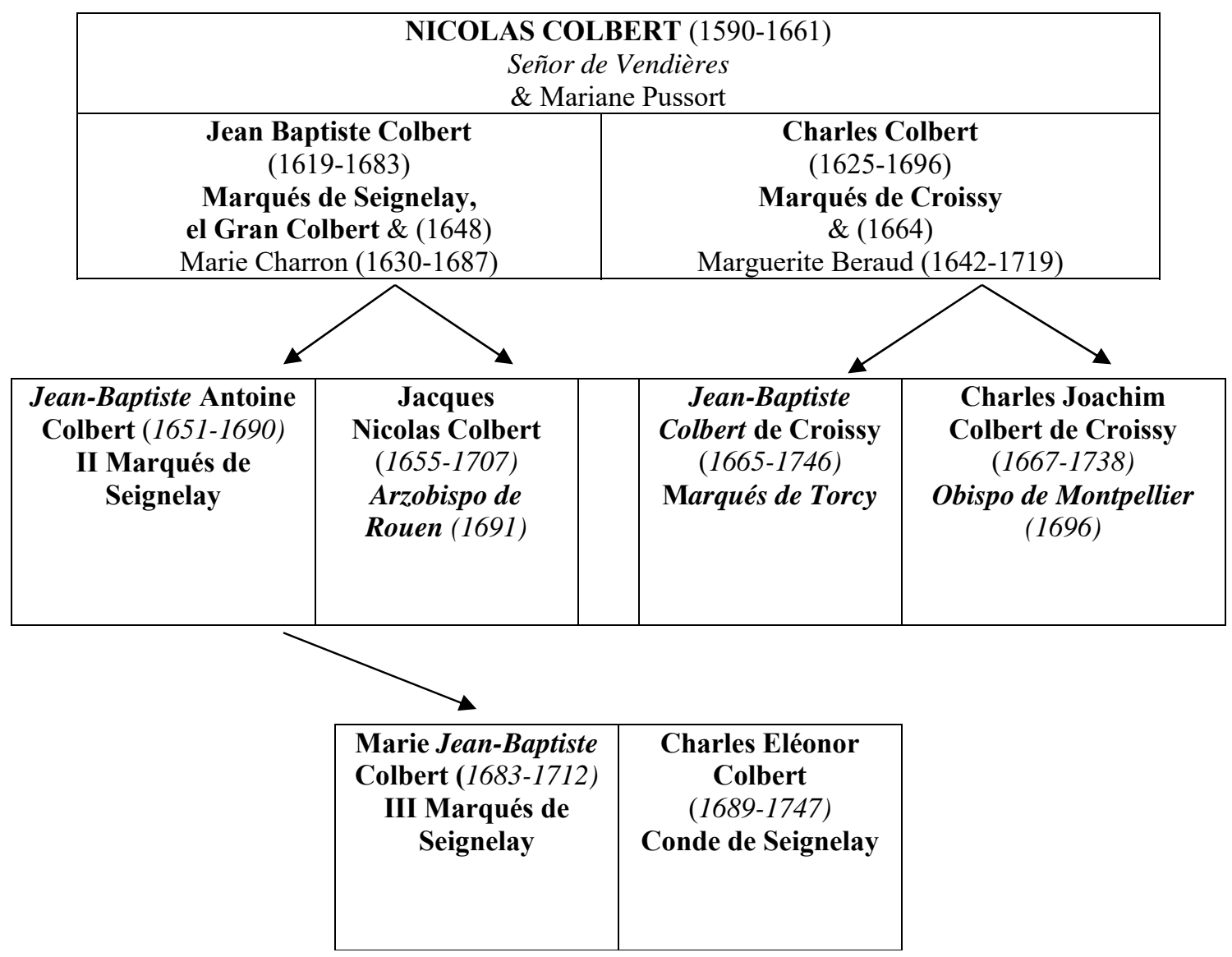

